\title{
EUDAIMONISTIC ARGUMENTATION
}

\author{
ANDREW ABERDEIN*
}

\begin{abstract}
Aвstract. Virtue theories of argumentation comprise several conceptually distinct projects. Perhaps the boldest of these is the pursuit of the fully satisfying argument, the argument that contributes to human flourishing. This project has an independently developed epistemic analogue: eudaimonistic virtue epistemology. Both projects stress the importance of widening the range of cognitive goals beyond, respectively, cogency and knowledge; both projects emphasize social factors, the right sort of community being indispensable for the cultivation of the intellectual virtues necessary to each project. This paper proposes a unification of the two projects by arguing that the intellectual good life sought by eudaimonistic virtue epistemologists is best realized through the articulation of an account of argumentation that contributes to human flourishing.
\end{abstract}

Virtue theories have lately enjoyed a modest vogue in the study of argumentation, echoing the success of more far-reaching programmes in ethics and epistemology. Virtue theories of argumentation (VTA) comprise several conceptually distinct projects, including the provision of normative foundations for argument evaluation and a renewed focus on the character of good arguers. One of the boldest of such projects is the pursuit of the fully satisfying argument, the argument that contributes to human flourishing. An analogous epistemic project has been pursued independently as eudaimonistic virtue epistemology. The two projects have much in common: both projects stress the importance of widening the range of cognitive goals beyond, respectively, cogency and knowledge; both projects emphasize social factors, the right sort of community being indispensable for the cultivation of intellectual virtues necessary to each project. This paper seeks to unite the two projects, by arguing that the intellectual good life sought by eudaimonistic virtue epistemologists is best realized through the articulation of an account of argumentation that contributes to human flourishing.

In the first section I survey VTA, with particular attention to the treatment of the fully satisfying argument. In the second section, I turn to eudaimonistic virtue epistemology, and discuss how it may be extended to encompass VTA. In the

*School of Arts \& Communication, Florida Institute of Technology, Melbourne FL. Date: April 15, 2019. 
third section, I address the specific issue of adversariality, arguing that the picture proposed in the previous section promises a resolution of a long-contested debate. Lastly, I conclude with a section briefly exploring the prospects for a combined eudaimonistic project.

1.

Dan Cohen has said that the "core ideas" of VTA "can fit on a couple of bumper stickers" (Cohen, 2013, 482):

For a Good Argument, Argue Well

Arguing Well Requires Good Arguers

In other words, VTA involves two successive steps away from much orthodox argumentation theory: firstly, a shift from the investigation and analysis of arguments as texts, broadly construed, to an appraisal of arguments as processes with participants; secondly, a concentration on the character of the participants-an expectation "that the admirable conduct of arguers ought to stem from virtues, inculcated habits of mind, rather than be accidental or occasional manifestations" (ibid.). In many respects, the first of these steps is the more consequential: the emphasis on virtue is arguably a more modest move than the shift of focus onto arguers from arguments. For that matter, just as not all virtue ethicists follow Aristotle in linking virtues to eudaimonia, neither do proponents of VTA necessarily see any analogous connection. Nonetheless, this connection does suggest a possible third step for VTA: from the character of arguers to the pursuit of human flourishing through the optimal conduct of argument.

Here are some of the virtues that Cohen focuses on: willingness to listen to others; willingness to modify one's own position; willingness to question the obvious; willingness to engage in serious argumentation (Cohen, 2005, 64). He situates them as Aristotelian means: extremes of excess or deficiency on their various axes comprise the corresponding vices. In my own attempt at a list of argumentational virtues, I complicate Cohen's picture with subheadings, including 
some much more familiar virtues, many of them drawn from what is known as responsibilist virtue epistemology

(1) willingness to engage in argumentation
(a) being communicative
(b) faith in reason
(c) intellectual courage
(i) sense of duty

(2) willingness to listen to others

(a) intellectual empathy

(i) insight into persons

(ii) insight into problems

(iii) insight into theories

(b) fairmindedness

(i) justice

(ii) fairness in evaluating the arguments of others

(iii) open-mindedness in collecting and appraising evidence

(c) recognition of reliable authority

(d) recognition of salient facts

(i) sensitivity to detail

(3) willingness to modify one's own position

(a) common sense

(b) intellectual candour

(c) intellectual humility

(d) intellectual integrity

(i) honour

(ii) responsibility

(iii) sincerity

(4) willingness to question the obvious

(a) appropriate respect for public opinion

(b) autonomy

(c) intellectual perseverance

(i) diligence

(ii) care

(iii) thoroughness (Aberdein, 2010, 175).

One way in which Cohen has framed his approach to VTA that differs from mine is that he asks what a maximally good argument would look like: "What would make an argument satisfying to the point that the participants could say at the end, 'Now that was a good argument'?" (Cohen, 2013, 477). He stresses that "The notion of an argument that is fully satisfying to its participants includes more than epistemic gains. It has to at least extend to cognitive gains more broadly,

${ }^{1}$ Virtue epistemologists are often distinguished between responsibilists, whose virtues mostly look like Aristotelian character virtues, and reliabilists, whose virtues are less obviously virtue-like: they are reliable cognitive processes (see, for example, Battaly. 2008. 644). 
including emotional, ethical, and possibly aesthetic aspects as well" Cohen, 2013. 478). He also notes that, while the virtues of argument may be necessary for the fully satisfying argument, they are not sufficient: "There are necessary conditions beyond the scope of the behavior and characters of the arguers, including the subject matter, the context, and the personal chemistry of the arguers" (Cohen and Miller, 2016, 459).

Other argumentation theorists, less directly associated with VTA, have also said some similar things. For example, Kathryn Norlock has proposed Nel Noddings' "receptivity" as a virtue of argument somewhat analogous to Cohen's willingness to listen, a mean between the uncritical acceptance of others' views and listening only in a defensive and uncharitable manner (Norlock, 2014, 2). Saliently, Norlock observes that for Noddings receptivity "seems to be essential to living fully as a person" (Noddings, 1984, 35). As Norlock notes, this suggests "the necessity of receptivity to eudaimonia" (ibid.). Moira Howes also asks "does happiness increase the objectivity of arguers", happiness here being thought of as not just subjective, but also eudaimonic:

Argumentative communities that support subjective and eudaimonic happiness will have an easier time strengthening these factors. In such contexts, arguers and audiences are likely to find it easier to change their minds in the face of evidence and imagine diverse, multifaceted audiences. They are more likely to be resilient and assertive in the face of negative commentary and find it easier to disagree respectfully. Overall, we can expect such communities to support a deeper commitment to acquiring an empirically adequate understanding of reality (Howes, 2014, 8).

So there are reasons to expect eudaimonia to have positive dividends in argumentational practice. Sharon Bailin, responding to Howes, introduces an important clarification:

Eudaimonia, in the Aristotelian sense, comes in fulfilling our human purposes, i.e., living in accordance with reason. Thus, on this account, critical thinking (and hence objectivity) is constitutive of eudaimonic happiness. So it's not so much that eudaimonia is 
a means to the end of objectivity in argumentation. It is rather that part of what it means to live well is to engage in rational pursuits and rational exchanges (Bailin, 2014, 3).

Arguing well is not just a ladder you climb up to get to a state of eudaimonia and may then throw away; it is actually an indispensable part of the goal you are seeking: critical thinking as a constitutive component of the good life.

The version of VTA that Cohen and I have defended may be seen as a "virtues in" account: in other words, possession of various virtues might be necessary to being a good arguer. The converse of this account is implicit in Bailin's idea that being a good arguer might be constitutive of what it is to lead the good life, and therefore that arguing badly could potentially corrupt and corrode your capacity to lead the good life. This idea has also been defended by Sherman Clark, a professor of law who has been writing about virtues in the context of legal persuasion for some years (Clark, 2003, 2011, 2013): the links between VTA and such closely related work in virtue jurisprudence are seldom addressed but hold great promise. Clark uses an example of an arguer with a perfectly legitimate goal of which they want to persuade some audience-his example concerns transport policy. Their view is perfectly respectable in itself, they're not secret racists who are trying to convince people of racist things for racist reasons; they just have a point of view on transport policy. But they might cynically appreciate that, if they add a touch of racist dog whistle to their transport policy arguments, they could win over some other people who were less admirable than themselves. ${ }^{2}$ But that would still be a bad thing to do. It might be, in the short term at least, successful; they might actually win some people over. But even if it is a good argument in that very reductive sense, it is certainly not a virtuous argument. As Clark says,

You might well choose to eschew that argument. Why? In part because you might consider it simply wrong to appeal to racism. But you might also quite sensibly realize that by making that sort of argument, even and perhaps especially if you did so indirectly and subtly, you would not just be appealing to but also helping to construct and reinforce fear and prejudice (Clark, 2011, 852).

${ }^{2}$ For a discussion of dog whistling in the context of VTA, see Aberdein 2018, 20.). 
What makes that kind of argument bad is not just a pious sense that one shouldn't be doing these kind of things, it's that you're actually making the world worse by indulging in such arguments and by encouraging other people to do likewise. That's the point that Clark is making, drawing on the idea that argument plays a role in constructing character:

The basic claim, however, is this: persuasion succeeds, if it succeeds, not by force of abstract logic, but by finding or making space in the constitutive world views-the beliefs, understanding, and priorities—of those we persuade. Unless we believe that the beliefs and understandings and priorities of those we persuade are always fully developed and permanently fixed, we should recognize that when we persuade we do not simply find, but, crucially, sometimes also may make space in their world views. When we persuade, we also teach; when we teach, we may construct. If so, we should think about what we may be doing to people when we persuade them (Clark, 2013, 1376).

This reverses the causal relationship between argument and character usually proposed in VTA. Clark is not just saying that you have to have the right sort of character in order to produce the right sort of arguments; he is saying you have to produce the right sort of arguments in order to have the right sort of character. When you succeed in persuading people of things, you succeed in some small way in shaping their character. If their character gets shaped by a lot of bad arguments then that will not lead anywhere good.

2.

A very specific project within virtue epistemology is what Britt Brogaard has called "eudaimonistic epistemology" (Brogaard, 2014a b b). Her proposal is that we can do epistemology successfully with a fundamental norm that emphasizes intellectual flourishing, rather than the sorts of things that fundamental epistemic norms usually emphasize, such as truth: 
Truth Norm: You ought to maximize your true beliefs and minimize your false beliefs (Brogaard, 2014C, 139) $3^{3}$

Brogaard's point is not that we should throw away the truth norm; on the contrary, we shouldn't say things that aren't true, and we should expect our norms to require that. But the truth norm need not be the fundamental norm. For Brogaard, "the fundamental epistemic norm is not to hinder intellectual flourishing" (Brogaard, 2014a, 15). We should still endorse the truth norm, but because the truth norm is in general conducive to intellectual flourishing, not because it is a fundamental norm. This general principle can be cashed out in specific instances. Brogaard suggests the following:

Intellectual Flourishing (belief): You should believe $p$ only if believing $p$ does not hinder intellectual flourishing.

Intellectual Flourishing (assertion): You should assert $p$ only if asserting $p$ does not hinder intellectual flourishing.

Intellectual Flourishing (action): You should treat $p$ as a reason for action only if treating $p$ as a reason for action does not hinder intellectual flourishing (Brogaard, 2014a, 15).

There is a much bigger story to be explored here as to whether or not this actually works. Brogaard has offered a full defence, as I shall not. She suggests some issues in epistemology, such as the value of knowledge, where treating the intellectual flourishing norm as more fundamental than the truth norm has clear advantages. Indeed, there are some very good reasons why we should not want to build our intellectual lives merely upon the acquisition of true beliefs. Were I to begin obsessively counting leaves I would acquire any number of true beliefs in short order, but that does not sound like any sort of good life (Brogaard, 2014a. 16). Since such behaviour would give me true beliefs at the cost of inhibiting any prospect of intellectual flourishing, it would be ruled in by the truth norm but ruled out by the intellectual flourishing norm.

Just as Cohen observes that argumentational virtues are necessary but not sufficient for a fully satisfying argument, Brogaard also notes that virtues alone do not suffice for intellectual flourishing: "While virtuous character traits and

${ }^{3}$ Brogaard credits versions of this view to numerous epistemologists, including Ralph Wedgwood, Tyler Burge, and Christopher Peacocke. 
well-functioning cognitive faculties and abilities can lead to a good intellectual life, there are many cases in which true belief flows from virtuous character traits or well-functioning cognitive faculties and abilities but in which the agent is not on the right track intellectually speaking" (Brogaard, 2014b, 97). In this respect, of course, both authors echo Aristotle (and differ from Plato or the Stoics) in treating eudaimonia as also dependent on other external goods, whose presence or absence may be a matter of luck (Hursthouse and Pettigrove, 2018, §2.1). Thus Brogaard observes that "Just as we cannot flourish, in Aristotle's sense, in solitude, so we cannot flourish intellectually outside an intellectual community" (Brogaard, 2014c. 140). Likewise Cohen avers that "The wrong time or place can be as detrimental to the success of an argument as bad arguers. But so can the wrong arguers, no matter how good they are" (Cohen, 2013, 484).

With only minor modifications, Brogaard's norm of intellectual flourishing can produce norms for argumentation. Her specific instances of the norm for belief and assertion apply without modification to fundamental actions within argumentation: the acceptance of conclusions and advancing of premisses. Indeed, assuming practical reasoning is included within the scope of argumentation, then her action instance might also find an unmodified application. But Brogaard does not contend that the instances that she specifies exhaust the possible applications of her fundamental norm. It is entirely within the spirit of her programme to propose further instances. For example:

Intellectual Flourishing (reasons): You should treat $p$ as a reason for accepting $q$ only if treating $p$ as a reason for accepting $q$ does not hinder intellectual flourishing

Connoisseurs of recent debates on the normativity of logic may recognise this instance of the norm as at least an echo of what has come to be known as a "bridge principle" (MacFarlane, 2004). That is, it bridges the two independent realms of logic and of normativity. Specifically, it may be seen as a possible way of spelling out the consequent in a generic bridge principle of the form "If $p \Rightarrow q$, then (normative claim about believing $p$ and $q$ )" (cf. Dutilh Novaes, 2015, 591; MacFarlane, 2004, 6) 4 However, since argumentation, at least according to VTA,

${ }^{4}$ At least if " $\Rightarrow$ " is understood as encompassing defeasible as well as deductive inference. I follow Dutilh Novaes in broadening MacFarlane's definition in this manner (Dutilh Novaes, 2015. 590). 
is an essentially dialogical activity, it seems appropriate that the instances of the norm of intellectual flourishing should be expressed in terms of a relationship between agents. For example, where a (perhaps defeasible) inference of the form $p \Rightarrow q$ obtains:

Intellectual Flourishing (proponent): If Opponent has granted $p$, then Proponent should put forward $q$ (and require Opponent to grant it) only if doing so does not hinder intellectual flourishing.

Intellectual Flourishing (opponent): If Opponent has granted $p$, and Proponent puts forward $q$, then Opponent should either grant $q$ or retract his endorsement of $p$, depending on which hinders intellectual flourishing the least.

These two instances are adapted from Catarina Dutilh Novaes's work extending John MacFarlane's account of bridge principles to dialogical contexts (Dutilh Novaes, 2015, $604 \mathrm{ff}$.). They may perhaps be seen as special cases of the reasons instance of the intellectual flourishing norm. Although this is the barest sketch of how one might apply a eudaimonistic epistemology to thinking about how arguments work, it should at least demonstrate that such an application appears worthy of further enquiry.

3.

As a test of this approach, I want to explore whether such an account can be made to work as a way of tackling the issue of adversariality. This is an important issue in argumentation, and perhaps an especially sharply focused issue in virtue argumentation, because there are a number of people who say that the adversariality of arguments is a problem. This stance is perhaps most familiar as a feminist critique but is not exclusively so (Rooney, 2010: Hundleby. 2013: Steenhagen, 2016). Such critics maintain that the way in which arguments tend to be couched, perhaps especially in philosophy, but in argumentation more generally, is needlessly damaging, because it is framed in adversarial terms. Trudy Govier has a response in terms of "minimum adversariality" (Govier, 1999, 55). Scott Aiken has refined his own version of this position over several iterations; here is a recent version: 
an arguer taking a critical line with one's own commitments is, for the purposes of the argument, both an opponent and an ally. The thought is that without the role-related duties of critical dialogue, there are moves of critical probing that must be performed that are, in their dialectical function, oppositional. However, this is yet in the service of a broader cooperative goal of dialectical testing of reasons and acceptability (Aikin, 2017, 16).

In other words, if you are concerned that we keep framing people as opponents, remember that they are also allies. Here is a similar approach to the same idea from Dutilh Novaes, that she frames hopefully as "virtuous adversariality", a strong cooperative, virtuous component which regulates and constrains the adversarial component. ... The picture that emerges is of philosophy as ongoing conversation between interlocutors who respectfully disagree with each other. Disagreement forces them to provide the best possible arguments to support their respective positions, and it is from the comparison between the best possible arguments for competing positions that more robust philosophical theories emerge. Interestingly, Grice's famous conversational maxims offer sensible principles on how to conduct such philosophical conversations, offering the right balance between adversariality and cooperation (Dutilh Novaes, 2014).

And, as a reminder, here are Grice's famous conversational maxims:

Quantity: (1) Make your contribution as informative as is required (for the current purposes of the exchange).

(2) Do not make your contribution more informative than is required.

Quality: Try to make your contribution one that is true.

(1) Do not say what you believe to be false.

(2) Do not say that for which you lack adequate evidence.

Relation: Be relevant.

Manner: Be perspicuous.

(1) Avoid obscurity of expression.

(2) Avoid ambiguity. 
(3) Be brief (avoid unnecessary prolixity).

(4) Be orderly (Grice, 1975, 45 f.).

Most of these are covered by the assertion instance of Brogaard's intellectual flourishing norm: You should assert $p$ only if asserting $p$ does not hinder intellectual flourishing. Indeed, Grice himself subordinates all of these maxims to a single norm:

Cooperative Principle: Make your conversational contribution such as is required, at the stage at which it occurs, by the accepted purpose or direction of the talk exchange in which you are engaged (Grice, 1975, 45).

It takes no great leap to see this as consistent with intellectual flourishing, at least as regards conversational exchanges. Certainly persistent and unmotivated disregard for this principle would seem likely to hinder intellectual flourishing.

4 .

Most discussion of VTA has emphasized the "virtues in" side, the contention that we need virtues of a certain type in order to argue the right way. However, the case I have made here is that we should also hope for "virtues out". Arguing well requires good, that is, virtuous arguers; but also arguing well, that is virtuously, is required for good arguers. If there are to be good arguers, there will need to be arguing well. More broadly, if intellectual flourishing cannot be attained in solitude, then there must be a community of interacting agents, whose potential for intellectual flourishing will only be realized individually if it is realized collectively. In any practical scenario, the interactions between these agents will exhibit disagreements and differences of opinion; that is, the basis for arguments. But these arguments ought to be fully satisfying ones, if the community is to continue to flourish. So, an indispensable component of any intellectually flourishing community will be fully satisfying arguments, which, if the treatment above is correct, will comply with instances of the intellectual flourishing norm. More broadly still, the satisfactory resolution of ethical debates will require such a community. Hence, if there are to be good people in general then there must be good argument. 


\section{REFERENCES}

Aberdein, Andrew. 2010. Virtue in argument. Argumentation 24(2): 165-179.

Aberdein, Andrew. 2018. Virtuous norms for visual arguers. Argumentation 32(1): $1-23$.

Aikin, Scott F. 2017. Fallacy theory, the negativity problem, and minimal dialectical adversariality. Cogency 9(1): 7-19.

Bailin, Sharon. 2014. Commentary on: Moira Howes's "Does happiness increase the objectivity of arguers?". In Virtues of Argumentation: Proceedings of the 1oth International Conference of the Ontario Society for the Study of Argumentation (OSSA), May 22-25, 2013, eds. Dima Mohammed and Marcin Lewiński. Windsor, ON: OSSA.

Battaly, Heather. 2008. Virtue epistemology. Philosophy Compass 3(4): 639-663.

Brogaard, Berit. 2014a. Intellectual flourishing as the fundamental epistemic norm. In Epistemic Norms: New Essays on Action, Belief, and Assertion, eds. John Turri and Clayton Littlejohn, 11-31. Oxford: Oxford University Press.

Brogaard, Berit. 2014b. Towards a eudaimonistic virtue epistemology. In Virtue Epistemology Naturalized: Bridges Between Virtue Epistemology and Philosophy of Science, ed. Abrol Fairweather, 83-102. Cham: Springer.

Brogaard, Berit. 2014c. Wide-scope requirements and the ethics of belief. In The Ethics of Belief: Individual and Social, eds. Jonathan Matheson and Rico Vitz, 130-145. Oxford: Oxford University Press.

Broome, John. 1999. Normative requirements. Ratio 12(4): 398-419.

Clark, Sherman J. 2003. The character of persuasion. Ave Maria Law Review 1(1): 61-79.

Clark, Sherman J. 2011. What we make matter. Michigan Law Review 1o9(6): 849-862.

Clark, Sherman J. 2013. To teach and persuade. Pepperdine Law Review 39(5): 1371-1399.

Cohen, Daniel H. 2005. Arguments that backfire. In The Uses of Argument, eds. David Hitchcock and Daniel Farr, 58-65. Hamilton, ON: OSSA.

Cohen, Daniel H. 2013. Virtue, in context. Informal Logic 33(4): 471-485.

Cohen, Daniel H. and George Miller. 2016. What virtue argumentation theory misses: The case of compathetic argumentation. Topoi 35(2): 451-46o.

Dutilh Novaes, Catarina. 2014. Virtuous adversariality as a model for philosophical inquiry. Presented at Edinburgh Women in Philosophy Group Spring Workshop on Philosophical Methodologies.

Dutilh Novaes, Catarina. 2015. A dialogical, multi-agent account of the normativity of logic. Dialectica 69(4): 587-609.

Govier, Trudy. 1999. The Philosophy of Argument. Newport News, VA: Vale Press.

Grice, Paul. 1975. Logic and conversation. In Syntax and Semantics, eds. Peter Cole and Jerry L. Morgan, vol. 3, 41-58. New York, NY: Academic Press.

Howes, Moira. 2014. Does happiness increase the objectivity of arguers? In Virtues of Argumentation: Proceedings of the 1oth International Conference of the Ontario Society for the Study of Argumentation (OSSA), May 22-25, 2013, eds. Dima Mohammed and Marcin Lewiński. Windsor, ON: OSSA.

Hundleby, Catherine. 2013. Aggression, politeness, and abstract adversaries. Informal Logic 33(2): 238-262. 
Hursthouse, Rosalind and Glen Pettigrove. 2018. Virtue ethics. In The Stanford Encyclopedia of Philosophy, ed. Edward N. Zalta. Stanford, CA: C.S.L.I.

MacFarlane, John. 2004. In what sense (if any) is logic normative for thought. Online at https://johnmacfarlane.net/normativity_of_logic.pdf

Noddings, Nel. 1984. Caring: A Feminine Approach to Ethics and Moral Education. Berkeley, CA: University of California Press.

Norlock, Kathryn J. 2014. Receptivity as a virtue of (practitioners of) argumentation. In Virtues of Argumentation: Proceedings of the 1oth International Conference of the Ontario Society for the Study of Argumentation (OSSA), May 22-25, 2013, eds. Dima Mohammed and Marcin Lewiński. Windsor, ON: OSSA.

Rooney, Phyllis. 2010. Philosophy, adversarial argumentation, and embattled reason. Informal Logic 30(3): 203-234.

Steenhagen, Maarten. 2016. Against adversarial discussion. Collingwood and British Idealism Studies 22(1): 87-112. 